\title{
Low Temperature Hydrothermal Synthesis of Biochar from Green Algae and Its Combustion Performance
}

\author{
Ning Xue \\ School of Resources and Materials, Northeastern University at Qinhuangdao, Qinhuangdao, China \\ Email: hnlgxzh@163.com
}

How to cite this paper: Xue, N. (2020) Low Temperature Hydrothermal Synthesis of Biochar from Green Algae and Its Combustion Performance. Open Access Library Journal, 7: e6898.

https://doi.org/10.4236/oalib.1106898

Received: October 14, 2020

Accepted: November 23, 2020

Published: November 26, 2020

Copyright ( $) 2020$ by author(s) and Open Access Library Inc.

This work is licensed under the Creative Commons Attribution International License (CC BY 4.0).

http://creativecommons.org/licenses/by/4.0/

(c) (i) Open Access

\begin{abstract}
The low temperature hydrothermal carbonization reaction of green algae was studied by combining with the low temperature hydrothermal carbonization technology. The hydrothermal carbon was prepared in the temperature range of $180^{\circ} \mathrm{C}-240^{\circ} \mathrm{C}$. The experimental results had been characterized in detail by oxygen bomb calorimeter, synchronous thermal analyzer and infrared spectrum analysis. The effects of reaction time, reaction temperature and salt concentration on hydrothermal carbonization and combustion were analyzed by studying the experimental conditions under the optimal calorific value. Results showed that algal carbonized, diversity and continental wooden biomass combustion process, and algae in the low temperature hydrothermal carbonization reaction of calorific value significantly increase, and comprehensive consideration of low temperature hydrothermal carbonization algae biomass to improve its calorific value is the best solution to time, salt concentration control in $8-10 \mathrm{~h}$, around $0.05 \%$, the reaction temperature is slightly greater than $240^{\circ} \mathrm{C}$. It provides a reference for the further research in the field of clean biomass and is of great significance for the development of algal biomass combustion function.
\end{abstract}

\section{Subject Areas}

Analytical Chemistry, Biological Materials

\section{Keywords}

Green Algae, Biomass, Low Temperature Hydrothermal Carbonization, Biochar

\section{1. 引言}

我国如今面临严峻的能源利用紧缺的问题。我在关注藻类生物质能够制 
氢时, 了解到藻类具有很大的利用空间, 其燃烧虽然无污染且燃烧率高, 但 是藻类的热值很低, 直接处理耗能极大, 而相比于热值最高的氢气来讲, 藻 类易储存、安全, 所以对于藻类的热值研究对能源问题的解决具有重大意义。 并且, 当今对于藻类的利用, 大部分仅限于水质的改善、化妆品的开发及最 普遍的水族装饰, 所以对于藻类作为生物质能源的研究, 对藻类的开发利用 也具有重大意义。

\section{1. 藻类生物质能及其利用现状}

藻相对于陆上生物质有其独特优势：(1) 生长在海里，不占用土地资源; (2) 藻没有叶、茎、根, 即没有无用生物量, 故整个藻体都可用于能源利用; (3) 生长速度快, 便于养殖, 如湤苔在适宜条件下每天每平方米可增加 $28 \mathrm{~g}$ (干 重); (4) 种类繁多, 且各类藻生长季节不一, 可以交替大量繁殖, 保证全年 资源充足，解决了生物质资源分散和受季节限制等大规模应用的瓶颈问题。

当今, 我国的生物质能主要来源于薪材、农林加工废弃物、禽畜粪便、 工业废弃物及城市生活垃圾等 $[1]$ 。在已有对于传统陆上木质类生物质能的研 究的情况下, 国内外学者已经开始着手于对新型生物质开发利用的研究, 国 外的 B. Ginzburg 研究了微藻液化制油, 而我国的吴庆余等人也研究了微藻制 取燃料的可能性 [2]。藻类作为一种重要的生物质能源, 受到了世界关注。日 本东京瓦斯和新能源产业总合开发机构(NEDO)用海藻作为原料制成甲烷气 体发电等。

\section{2. 低温水热炭化技术的优势及利用现状}

水热炭化技术最早是于年等人在对纤维素进行炭化转化试验中第一次提 出的, 直到上世纪末这种技术才得到系统的研究[3]。近年来水热炭化技术开 始在材料合成领域被逐渐关注。如糖类物质经水热炭化后能够形成炭微球颗 粒, 而炭微球作为一种新型材料, 具有非常好的热化学稳定性和良好的导热 导电性, 在许多领域有着巨大的潜在应用价值。在环境领域, 研究人员利用 水热炭化技术处理废弃生物质, 如农作物秸秆、树叶、木屑、餐㢄垃圾等并 将这些物质转化为高储能的碳材料 [4]。生物质经过水热反应可产生两种产 物：一类是不溶于水的固相产物, 其结构以碳及其衍生物为主, 有些微观形 貌呈球形, 表面含有大量羟基、羰基等亲水性官能团; 另一类是可溶性产物, 如糠醛类化合物、有机酸和醛类等, 这类产物燃烧热值高, 如纤维素水热分 解释放的 5-HMF, 其单位燃烧高位热值为 $22.06 \mathrm{MJ} / \mathrm{kg}$, 远高于纤维素自身的 燃烧热值(17-18 MJ/kg), 因而是重要的能源替代品[5]。

生物质的水热碳化法和高温热解法相比具有反应条件温和、反应周期较 短、反应过程不易产生二次污染、操作简单、成本低廉、应用范围广等优点, 并且反应以生物质作为原料, 水作为反应溶剂, 是优于其他热化学反应工艺 的绿色环保的可持续性碳转化途径[6], 而且水热碳化法能够保证较高的得率 和成本低廉这一发展需求。利用水热碳化法可制备出性能优良的生物质炭能 源材料[7], 而且由于反应过程中纤维素、半纤维素等生物质原料在高温高压 下发生水解、聚合和缩聚反应, 使得水热形成的碳材料相比原生物质具有更 
高的燃烧热值, 且这类材料易于燃烧、在较低燃烧温度范围内就能够释放出 较高热量, 易于储存和运输, 因此研究这种碳材料作为生物质能源的转化利 用形式具有巨大的研究价值。

\section{3. 研究目的与意义}

目前, 藻类的碳化技术主要以高温热解法为主, 而高温热解法温度过高 $\left(1000^{\circ} \mathrm{C}\right.$ 以上), 以能源利用为目的的水热转化法研究较少, 文献中鲜有报道 [8]。因此, 本论文以天然水体中常见的藻类——绿藻为研究对象, 采用相对 于高温热解实验温度较低的低温水热碳化法制备藻类生物质水热碳, 并研究 制备过程中如反应温度、反应时间以及催化剂浓度等对制得水热碳的热值、 燃烧性能、挥发分、灰分、固定碳等的影响, 以寻找一种低值废弃物的最佳 分离、转化和能源利用途径。

\section{2. 实验材料与方法}

\section{1. 实验材料}

本实验使用的原料为绿藻, 采集地点位于上海市崇明区某生态农场。样 品采集后经重力滤干并带回实验室经去离子水反复洗涤以去除藻中泥沙等悬 浮颗粒物, 为防止绿藻变质且保留活性, 在冰箱中 $4^{\circ} \mathrm{C}$ 恒温保存。湿基样品 经烘箱 $105^{\circ} \mathrm{C}$ 烘干 $24 \mathrm{~h}$ 后得到干基藻类样品。本试验所使用的化学试剂如表 1 所示。水热反应过程所使用的反应装置为具有聚四氟乙烯内祄的 $50 \mathrm{~mL}$ 高 压反应釜, 并在具有自动加热装置的马弗炉中进行。

\section{2. 实验方法}

\subsection{1. 水热炭的制备方法及流程}

将干燥后的绿藻样品装入 $50 \mathrm{~mL}$ 的反应釜中, 并向其加入 $40 \mathrm{ml}$ 去离子 水及硫酸铁溶液 (液固比约为 5:1), 待充分混合后, 将各样品置于马弗炉中, 按所需的实验条件设置升温程序(设置升温时间、反应温度及反应时间), 进 行水热反应, 待反应结束后自然冷却至室温, 将样品取出并用浓度为 $1+9$ 的 $\mathrm{HCl}$ 洗涤后再反复用去离子水洗涤直至洗出液的 $\mathrm{pH}$ 值稳定时, 将样品过滤 并在 $105^{\circ} \mathrm{C}$ 下烘干至恒重, 密封收集待测。该实验的设计流程如图 1 所示。

\subsection{2. 水热炭的制备条件优化}

确定以反应温度、反应时间和盐浓度为因素, 以水热炭的高位燃烧热值 为指标, 采用正交表 $\mathrm{L} 9\left(3^{4}\right)$ 正交表安排实验, 做三因素三水平的正交试验, 因素水平表见表 2。

表 1. 本试验所使用的主要化学试剂

\begin{tabular}{cccc}
\hline 试剂名称 & 纯度等级 & 生产商 & 分子量 \\
\hline $\mathrm{Fe}_{2}\left(\mathrm{SO}_{4}\right)_{3} \cdot \mathrm{xH}_{2} \mathrm{O}$ & 分析纯 $\mathrm{AR}$ & 国药集团化学试剂有限公司 & 399.88 \\
盐酸 & 分析纯 $\mathrm{AR}$ & 国药集团化学试剂有限公司 & 36.46 \\
\hline
\end{tabular}




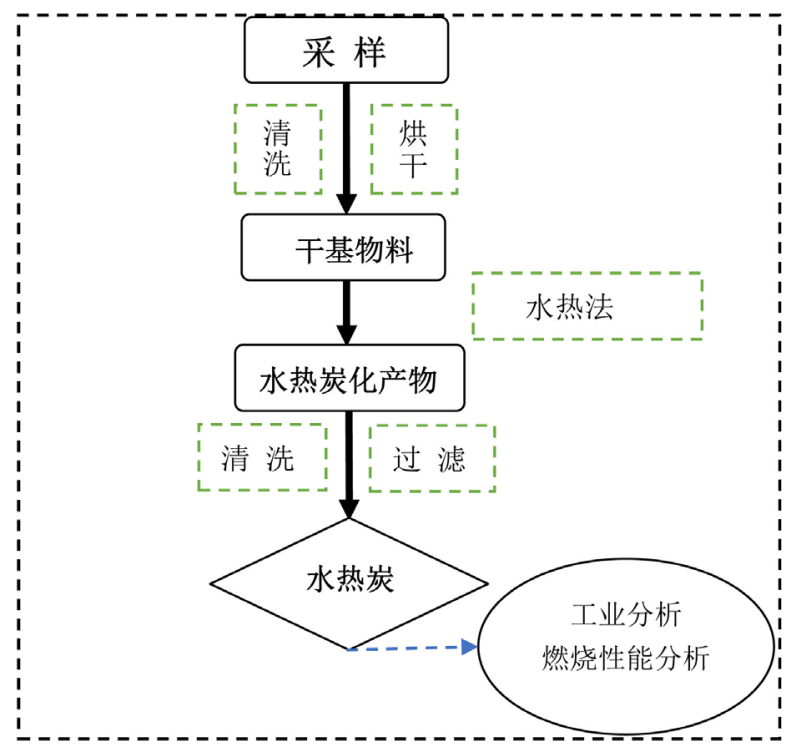

图 1. 绿藻合成生物质水热炭的实验流程示意图

表 2. 三因素三水平正交实验设计表

\begin{tabular}{cccc}
\hline 水平 & 反应温度 $\mathrm{A}\left({ }^{\circ} \mathrm{C}\right)$ & 反应时间 $\mathrm{B}(\mathrm{h})$ & 催化剂浓度 $\mathrm{C}(\mathrm{wt} \%)$ \\
\hline 1 & 180 & 6 & 0.01 \\
2 & 200 & 9 & 0.05 \\
3 & 240 & 12 & 0.10 \\
\hline
\end{tabular}

\section{3. 样品分析方法}

\subsection{1. 热值的测定}

原料及所有水热炭的热值由 XRY-1A+氧弹式热量仪测定。选取实验样品 约为 $5 \mathrm{mg}$, 放入氧弹瓶中, 瓶底内置 $10 \mathrm{ml}$ 水, 点火丝接触藻样表面, 不接 触瓶以防止点火短路, 拧紧瓶身后充入氧气待用; 仪器内筒内置约 $2300 \mathrm{ml}$ 水, 内筒温度 $\mathrm{t}\left({ }^{\circ} \mathrm{C}\right)$ 设置为外筒温度 $-5^{\circ} \mathrm{C} \leq \mathrm{t} \leq$ 外筒温度 $-3^{\circ} \mathrm{C}$ 。将氧弹瓶放入 仪器卡槽中, 测定方式选取为瑞芳法测定。在仪器热容值约为 $15,545 \mathrm{~J} / \mathrm{k}$ 、初 始温度为内筒温度、通入空气的条件下, 升温约 $30 \mathrm{~min}$ 。测定完毕, 获得实 验数据。

\subsection{2. 燃烧性能分析}

燃烧性能是指材料在氧气中完全燃烧时在不同燃烧温度区间所放出的热 量及质量的变化, 用以定性描述样品中各组成比例。采用 $\mathrm{TA}$ 的同步热分析 仪对样品在氧气气氛中以 $5^{\circ} \mathrm{C} / \mathrm{min}$ 的升温速度进行热量和质量变化测试, 计 算水热炭的基本工业性质及燃烧过程的初始燃烧温度 $\left(T_{\mathrm{i}}\right)$ 和最大燃烧温度 $\left(T_{\mathrm{m}}\right)$ 。

\subsection{3. 挥发分、灰分、固定碳的分析}

先称量好坩埚的质量, 记为 $M_{0}$, 然后将干燥好的样品放入坩埚中称取质 
量记为 $M_{1}$ 。放入马弗炉中, 将温度调至 $600^{\circ} \mathrm{C}$, 维持 2 个小时。待温度降至 室温后取出称量出质量, 记为 $M_{2}$ 。再次将样品放入马弗炉中, 设定炉内温度 为 $800^{\circ} \mathrm{C}$, 维持两个小时。待温度冷却至室温后, 将其取出并称量, 记为 $M_{3}$ 。 带入公式 2.1 , 即可求出水热炭中挥发分、固定碳、灰分的质量分数。

公式 2.1:

$$
\begin{gathered}
\text { 挥发分含量 }(\mathrm{VS})=\left(M_{1}-M_{2}\right) /\left(M_{1}-M_{0}\right) \times 100 \% \\
\text { 灰分含量 }(\mathrm{A})=\left(M_{1}-M_{3}\right) /\left(M_{1}-M_{0}\right) \times 100 \% \\
\text { 固定碳含量 }(\mathrm{FC})=(100 \%-\text { 挥发分-灰分 }) \times 100 \%
\end{gathered}
$$

\section{3. 实验结果与讨论}

\section{1. 水热碳化实验条件的优化}

对绿藻在不同水热温度、水热时间和催化剂盐浓度下的产物按照表 2 所 示进行实验, 以氧弹热量计测试所得水热碳的高位燃烧热值(HHV)为研究指 标, 测试结果如表 3 所示, 同时, 以 $\mathrm{I}$ 水平下的三次实验结果的平均值 $K 1$, $K 2$ 和 $K 3$ 分别计算其极差 $R\left(R=K_{\text {max }}-K_{\text {min }}\right)$ 。

经过对样品的热值测定, 由图 2 可清晰看到一样品热值高于其余样品, 数据比对可得知样品 4 (反应 $9 \mathrm{~h}$ 、温度 $180^{\circ} \mathrm{C}$ 、铁盐浓度 $0.05 \%$ ) 热值最高, 约为 $24,483 \mathrm{~J} / \mathrm{g}$ 。

从上面可以看出, 以燃烧热值为指标, 根据各因素的极差大小所反映得 到的因素影响顺序为反应时间 > 铁盐浓度 > 反应温度, 取 KI 最大值所对应 的水平为最佳水平, 取各水平最佳水平进行组合可得到 $\mathrm{A} 2 \mathrm{~B} 3 \mathrm{C} 2$, 即按照正交 试验设计所得水热炭最佳的反应条件为反应时间 $9 \mathrm{~h}$, 反应温度 $240^{\circ} \mathrm{C}$, 盐浓

\section{表 3. 正交试验结果分析}

\begin{tabular}{ccccc}
\hline 实验列号 & 反应时间 $\mathrm{A}(\mathrm{h})$ & 反应温度 $\mathrm{B}\left({ }^{\circ} \mathrm{C}\right)$ & 铁盐浓度 $\mathrm{C}(\%)$ & 热值 $\mathrm{q}(\mathrm{J} / \mathrm{g})$ \\
\hline 1 & 6 & 180 & 0.01 & 19,784 \\
3 & 6 & 200 & 0.05 & 19,929 \\
4 & 6 & 240 & 0.10 & 20,809 \\
5 & 9 & 180 & 0.05 & 24,483 \\
6 & 9 & 200 & 0.10 & 23,987 \\
7 & 9 & 240 & 0.01 & 24,064 \\
8 & 12 & 180 & 0.10 & 22,078 \\
9 & 12 & 200 & 0.01 & 21,597 \\
$K 1$ & 12 & 240 & 0.05 & 23,996 \\
$K 2$ & 20,174 & 22,115 & 21,815 & \\
$K 3$ & 24,178 & 21,998 & 22,803 & \\
$R$ & 22,557 & 22,956 & 22,291 & \\
\hline
\end{tabular}




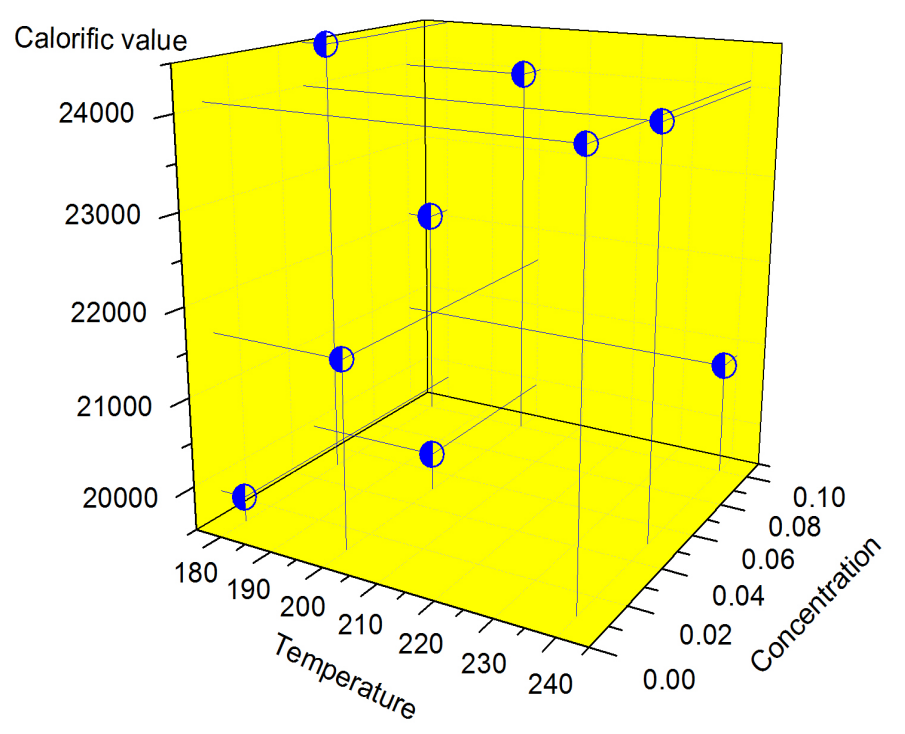

图 2. 样品热值三维柱状图

度 $0.05 \%$ 。由此可见, 在绿藻低温合成水热炭的过程中, 反应时间对产物燃 烧热值的影响最大, 这是由于长时间的水热反应虽有利于生物质中纤维素、 多糖等化合物的水解, 但同时会使得沉积在碳表面的高热值水解产物如 5-羟 基糠醛(5-HMF) 随反应时间延长而发生降解并生成低分子量的小分子有机 酸, 如甲酸、乙酸和糠醛类化合物, 这些化合物燃烧热值低且易溶解于极性 的溶液相中, 使得固相产物的热值降低。高温有利于纤维素、半纤维素等生 物质中大分子氧桥断裂, 并加速分解生成物低聚体或二聚体产物向葡萄糖、 木糖、甘露糖等单糖化合物转变, 该反应有利于后期这些糖类化合物继续脱 水形成高热值糠酫类化合物。本试验中, 通过在溶剂中投加铁盐可以催化水 热反应中生物质向 5-HMF 转化, 从而提高水热炭的燃烧热值, 而过量的添加 催化剂同时易使 5-HMF 转化为乙酰丙酸和甲酸转化, 而这两者的燃烧热值仅 有 $20.09 \mathrm{MJ} / \mathrm{kg}$ 和 $15 \mathrm{MJ} / \mathrm{kg}$; 另外, 由于加入铁盐, 使得在高温高压环境中体 系中的铁离子易通过氧化还原与溶液中的溶解氧作用催化产生自由基, 而由 于自由基的强亲电性容易引发大分子的自由基聚合, 从而有利于加速水热碳 的形成。

\section{2. 水热碳工业组成分析}

图 3 为不同水热反应时间下制得水热碳的含水率、挥发分、固定碳以及 灰分的含量示意图, 由图可见, 随着水热反应时间的增加, 水热碳中挥发分 的含量持续增加, 这可能与藻中纤维素等大分子的水解和降解有关, 反应时 间越长更有利于大分子有机物向低分子量有机酸的转化 [9], 从而通过表面吸 附等作用粘附在碳载体上形成挥发分。反应 $9 \mathrm{~h}$ 的水热碳其挥发分、固定碳 和灰分的含量分别为 $65.0 \% 、 29.0 \%$ 和 $5.4 \%$, 可以看到, 由于 $9 \mathrm{~h}$ 为形成水热 碳的最高热值合成时间, 因此猜测, 这部分挥发分主要由糠醛类化合物组成, 这些化合物通过化学或者物理吸附作用粘附在生物碳表面, 形成该条件下藻 类水热碳的主要燃烧主成分。 


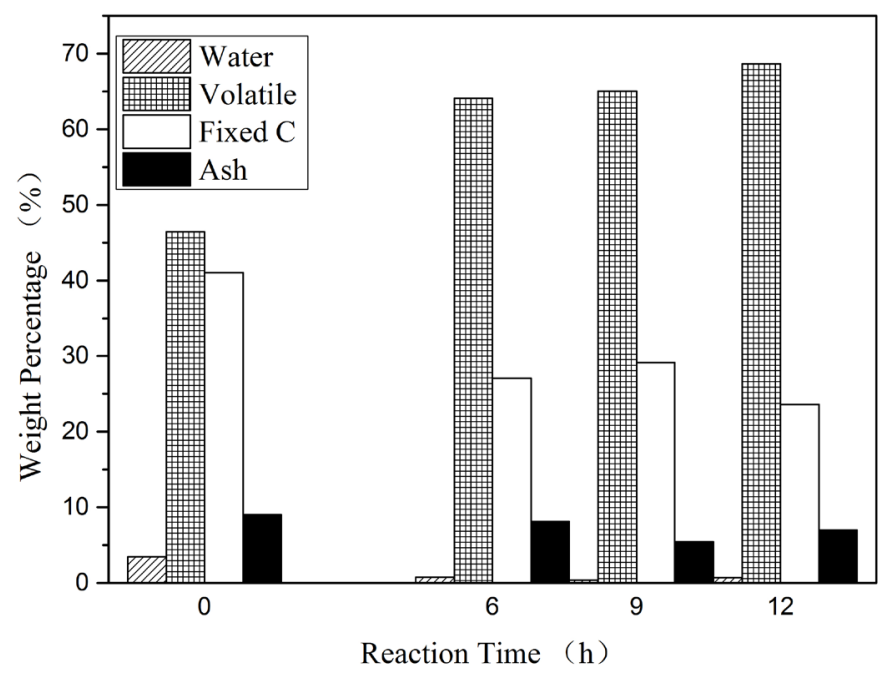

图 3. 不同水热时间对藻类合成水热碳挥发分、固定碳和灰分含 量的影响

图 4 和图 5 分别为不同反应温度和不同铁盐投加浓度对水热碳挥发分、 固定碳和灰分含量的影响, 可以看出, 随着反应温度的提高生成物挥发分的 含量逐渐增大, 由 $180^{\circ} \mathrm{C}$ 时的 $55.8 \%$ 增加到 $240^{\circ} \mathrm{C}$ 时的 $65 \%$, 同时固定碳含 量则由 $36.8 \%$ 降低至 $29.1 \%$, 证明水热反应温度加速了物料由固定碳向挥发分 的转变。从图 5 中可以看到, 增加盐浓度不会明显增加产物挥发分的比例, 这可能与盐催化分解产生的小分子有机酸的性质有关, 这些亲水的有机酸不 易被吸附在疏水性碳物料表面, 从而使产物表面吸附的挥发分含量保持相对 稳定[10]。

\section{3. 产物燃烧特性分析}

图 6 为绿藻在氧气气氛下升温速率为 $5^{\circ} \mathrm{C} / \mathrm{min}$ 条件下燃烧得到的 TG-DTG 曲线。按照失重速率大小可以将绿藻的燃烧分为三个阶段: 第一阶 段为 $0-100^{\circ} \mathrm{C}$, 失重约 $3.5 \%$, 主要由生物质原料的脱水而形成; 第二阶段为 $200^{\circ} \mathrm{C}-400^{\circ} \mathrm{C}$, 失重约 $58 \%$, 这一阶段主要对应生物质中易挥发性碳的燃烧 过程; 第三阶段为 $400^{\circ} \mathrm{C}-600^{\circ} \mathrm{C}$, 对应生物质物料中难挥发部分的表面燃烧, 对应的热烧失量为 $31.9 \%$ 。

\section{4. 反应时间对燃烧特性的影响}

经过对以图 7、图 8、图 9 的对比分析可以看出, 第二阶段速率变化明显 大于第三阶段速率变化。在燃烧的第二阶段中, 反应时间为 $9 \mathrm{~h}$ 的样品速率 变化更加明显, 能量相比于固定碳形式的转换, 更多地储存在有机分中。

\section{5. 反应温度对燃烧特性的影响}

经过对以图 10、图 11、图 12 的对比分析可以看出, 第二阶段速率变化 明显大于第三阶段速率变化。在燃烧的第二阶段中, 反应时温度为 $240^{\circ} \mathrm{C}$ 的 样品速率变化更加明显, 能量相比于固定碳形式的转换, 更多地储存在有 


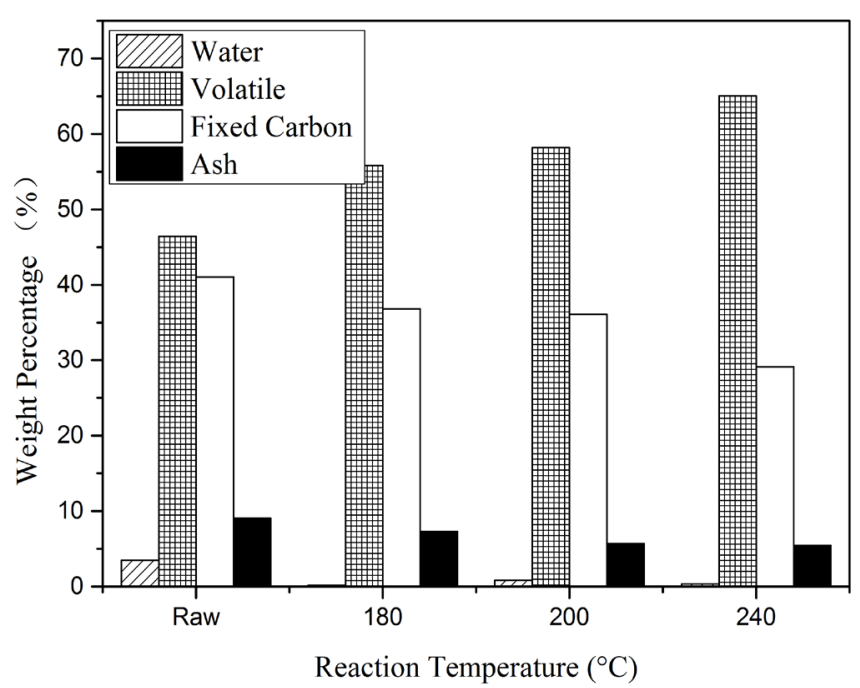

图 4. 不同反应温度对藻类水热碳挥发分、固定碳和灰分含量的 影响

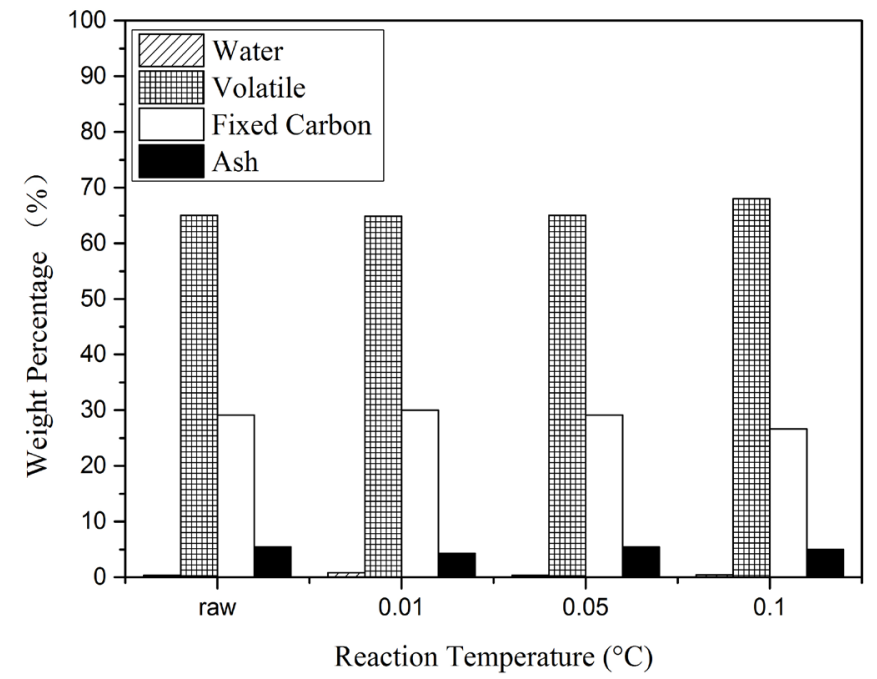

图 5. 不同盐浓度对藻类水热碳挥发分、固定碳和灰分含量的影响

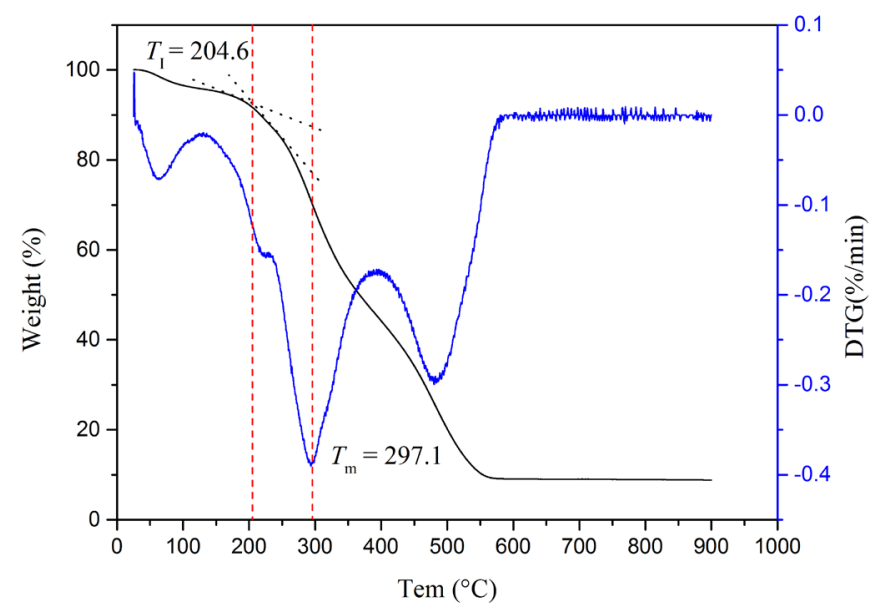

图 6. 绿藻原样燃烧特性曲线 


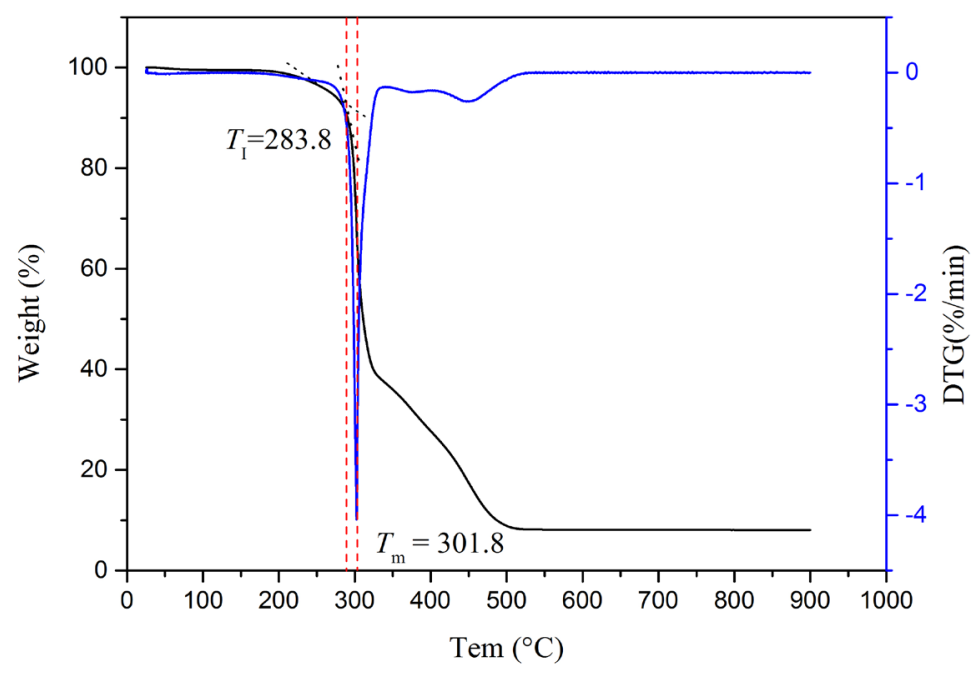

图 7. 反应时间 $6 \mathrm{~h}$ 绿藻燃烧特性曲线

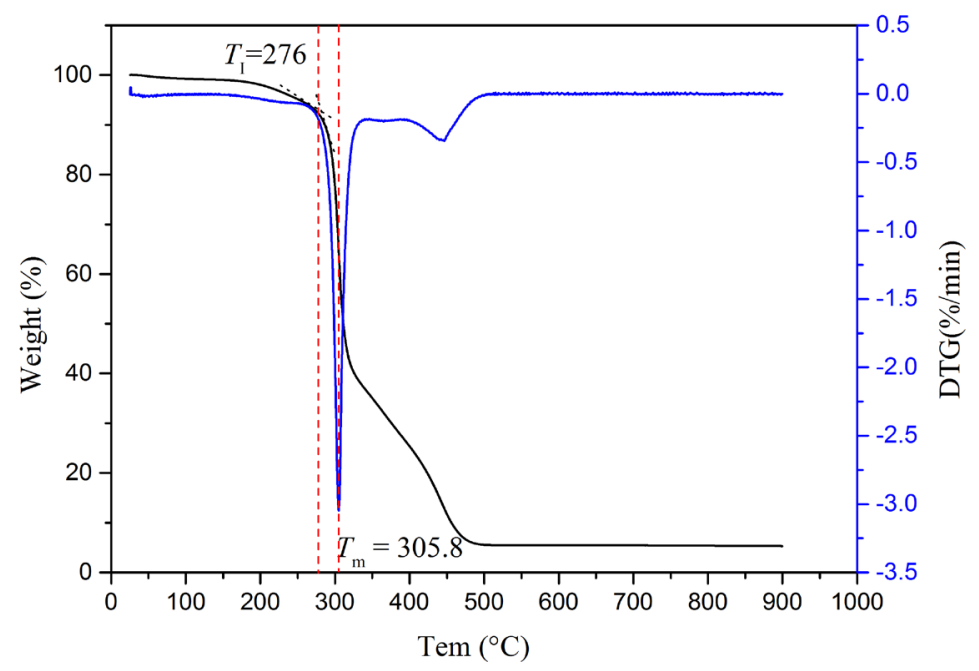

图 8. 反应时间 $9 \mathrm{~h}$ 绿藻燃烧特性曲线

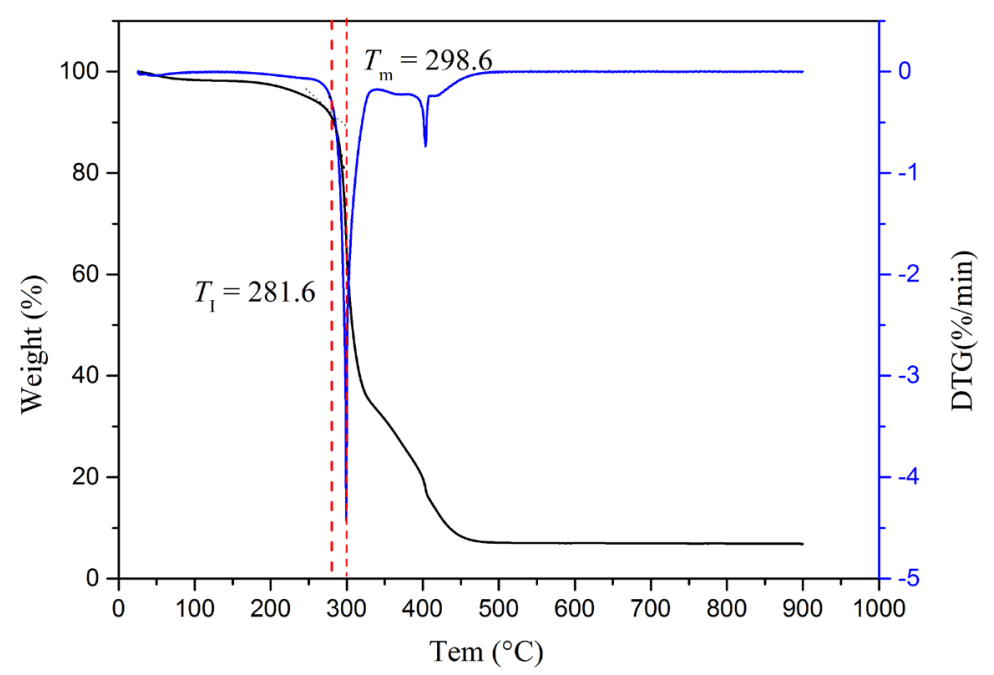

图 9. 反应时间 $12 \mathrm{~h}$ 绿藻燃烧特性曲线 


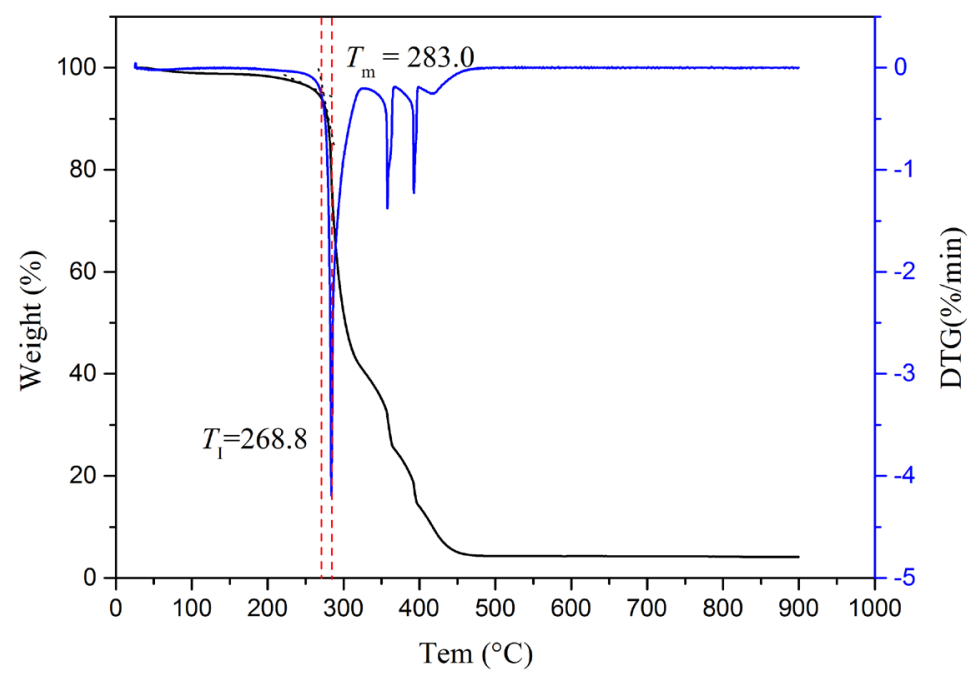

图 10. 反应温度 $180^{\circ} \mathrm{C}$ 燃烧特性曲线

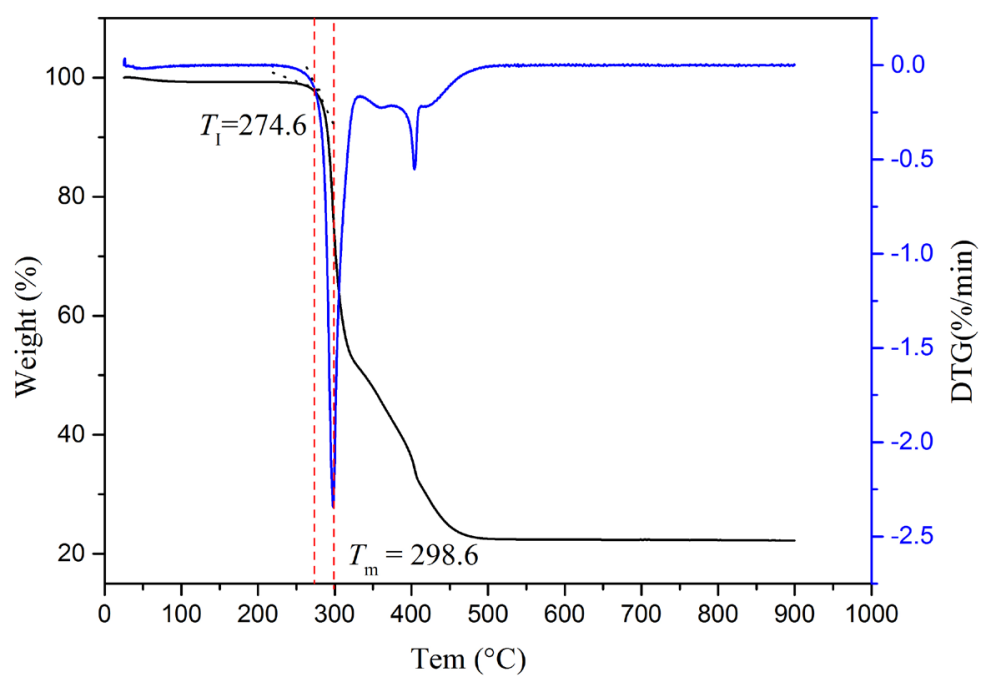

图 11. 反应温度 $200^{\circ} \mathrm{C}$ 燃烧特性曲线

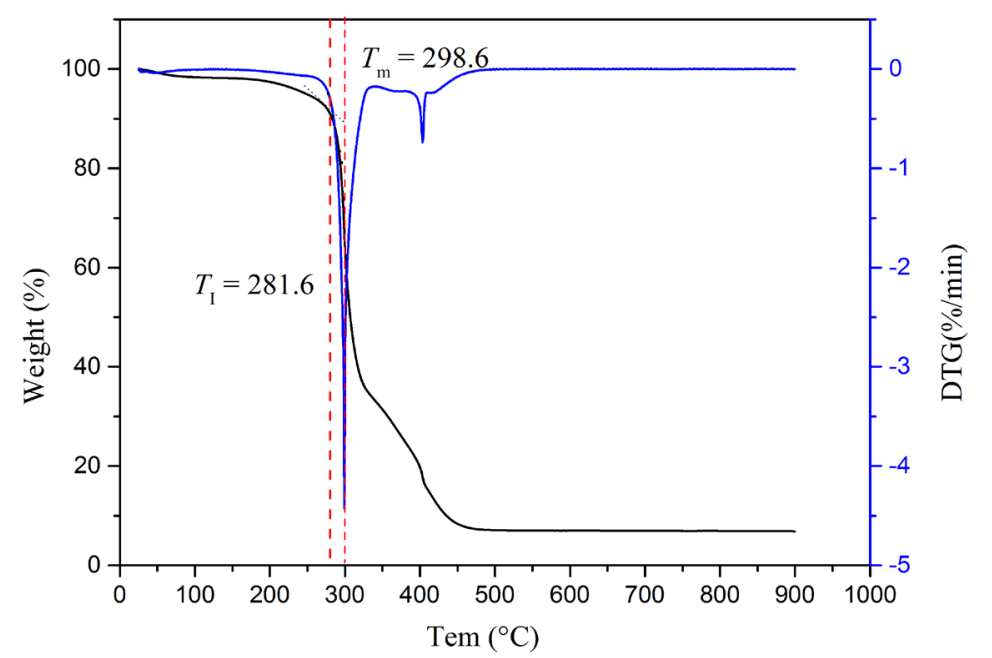

图 12. 反应温度 $240^{\circ} \mathrm{C}$ 燃烧特性曲线 
机分中。

\section{6. 反应中铁盐浓度对燃烧特性的影响}

经过对以图 13、图 14、图 15 的对比分析可以看出，第二阶段速率变化 明显大于第三阶段速率变化。在燃烧的第二阶段中，铁盐浓度为 $0.05 \%$ 的样 品重量损失明显, 速率变化更快, 能量相比于固定碳形式的转换, 更多地储 存在了有机分中。

\section{4. 结论}

本文采用藻类生物质绿藻作为原材料, 分别在不同盐浓度、不同反应温 度及不同的反应时间条件下进行水热炭化实验。并利用元素分析仪、同步热 分析仪、红外光谱分析等手段进行了较为详细的表征。所得结论如下：

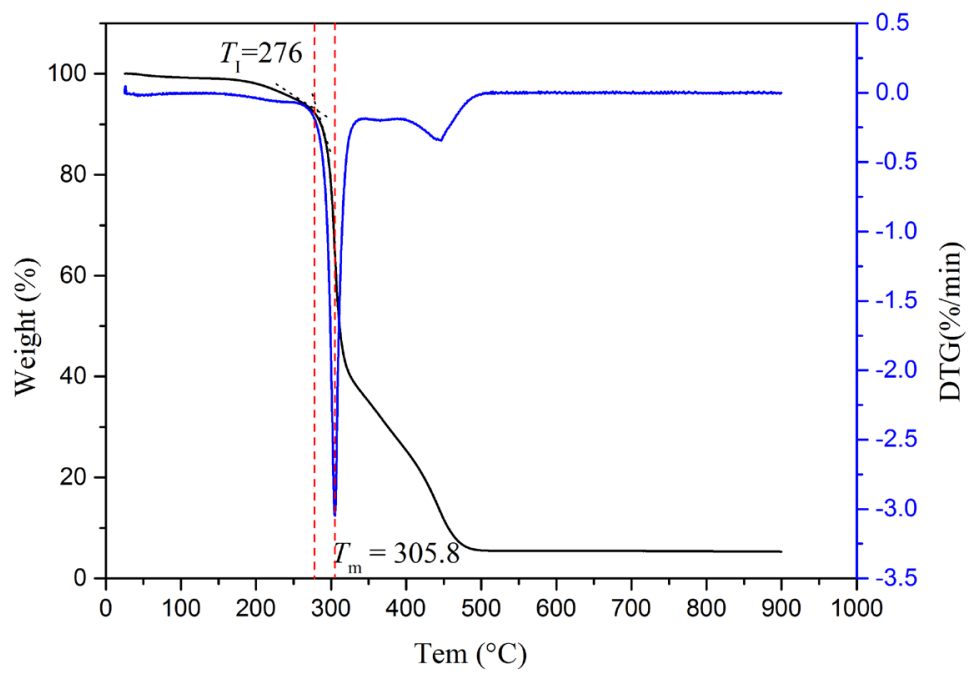

图 13. 铁盐浓度 $0.01 \%$ 燃烧特性曲线

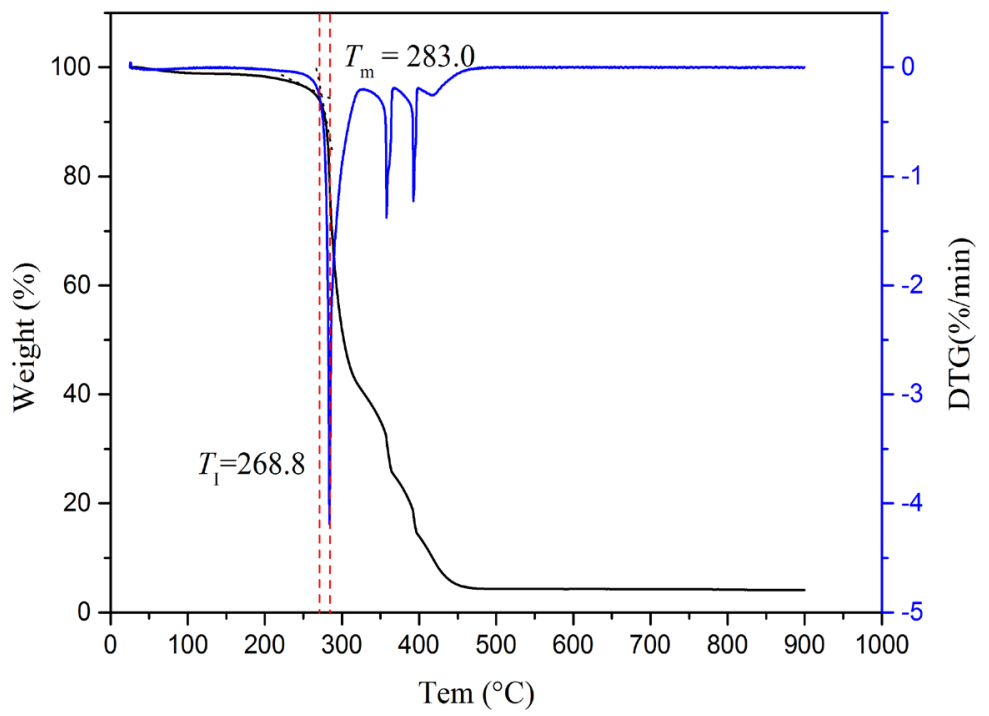

图 14. 铁盐浓度 $0.05 \%$ 燃烧特性曲线 


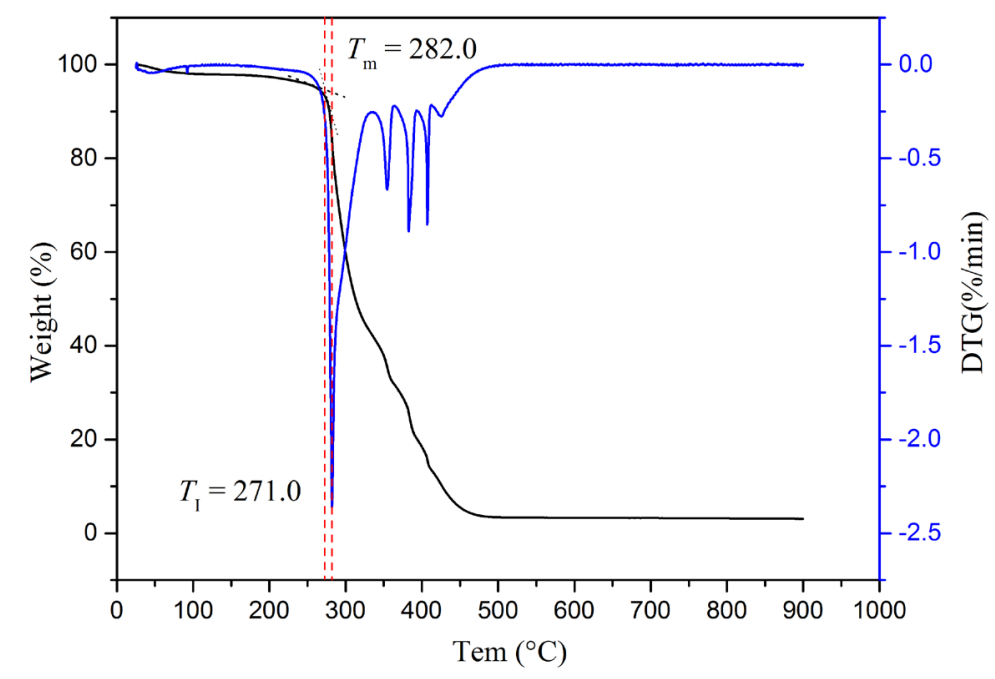

图 15. 铁盐浓度 $0.10 \%$ 燃烧特性曲线

实验结果表明，

1）盐浓度的提高有利于生物质水热碳化反应盐浓度的提高, 虽然有利于 水热碳化，但不易过大。

2) 在不同温度条件下反应, 发现温度的提高亦能够促进水热碳化过程中 脱水、脱羧反应的进行, 并且热值的变化与温度 $\left(\mathrm{t}>180^{\circ} \mathrm{C}\right)$ 变化呈正相关, 可 见温度提高有利于藻类的热值提升。

3) 在不同的水热时间下反应, 反应时间的延长使水热碳化过程中脱水、 脱羧进行地更加完全, 但是当时间增加到一定的程度后, 脱水、脱羧反应会 达到平衡, 因此反应温度的延长虽然有利于水热碳化, 但不易过长。

由此, 实验的进行得到了提高藻类热值的最佳反应条件为时间、盐浓度 分别控制在 $8-10 \mathrm{~h} 、 0.05 \%$ 左右, 反应温度略大于 $240^{\circ} \mathrm{C}$, 为藻类的进一步利 用提供了一定的借鉴，同时为新能源材料的开发提供了一大方向。

\section{致 谢}

感谢上海市科协为本项目的开展提供的支持, 感谢上海理工大学环境与 建筑学院实验室的支持。

\section{Conflicts of Interest}

The author declares no conflicts of interest regarding the publication of this paper.

\section{References}

[1] 孙克静, 张海荣, 唐景春. 不同生物质原料水热生物炭特性的研究[J]. 农业环境 科学学报, 2014, 33(11): 2260-2265.

[2] 糜梦星, 邢献军, 张学飞, 陈泽宇, 朱成成, 付一轩. 基于分布式改良 Coats-Redfern 法的梧桐叶燃烧动力学研究 [J]. 太阳能学报, 2019(9): 2672-2679.

[3] 王进丹, 张苏, 等. 园林绿化废弃物资源化利用的探讨 [J]. 浙江农业科学, 2013(8): 1034-1038. 
[4] 王德元. 生物质能利用系统综合评价研究[D]: [硕士学位论文]. 武汉: 华中科技 大学, 2008: 1-109.

[5] 吴庆余, 穆西南, 惠铭. 两种钻藻热解产出的气态和液态烃类 [J]. 微体古生物学 报, 1994, 11(1): 109-114.

[6] 查湘义. 水热处理温度对污泥中碳、氮、磷溶出的影响 [J]. 中国环境管理干部学 院学报, 2018(3): 63-66.

[7] 王爽, 姜秀民, 王宁, 于立军, 李祯, 何培民. 海藻类生物质的热解和燃烧特性的 研究[J]. 动力工程, 2009(6): 596-601.

[8] 吴倩芳. 水热碳化废弃生物质的研究进展 [J]. 环境污染与治理, 2012, 34(7): 70-79.

[9] 乔娜. 玉米芯和松子壳的水热碳化及其产物吸附性能研究 [D]: [硕士学位论文]. 大连: 大连理工大学 2015: 1-65.

[10] 何明会, 陈洪粉, 阮兵, 刘东阳, 罗苏丽. 烟草废弃生物质热解实验研究[J]. 科技 创新与应用, 2016(20): 3-4.

\section{Appendix (Abstract and Keywords in Chinese) 绿藻低温水热合成生物炭及燃烧性能研究}

摘要: 将绿藻与低温水热炭化技术结合, 研究了绿藻的低温水热炭化反 应, 在 $180^{\circ} \mathrm{C}-240^{\circ} \mathrm{C}$ 温度范围内制备水热炭。利用氧弹热量仪、同步热分析 仪、红外光谱分析等手段进行了较为详细的表征。通过研究最佳热值下的实 验条件, 分析了反应时间、反应温度及盐浓度对其水热炭化和燃烧过程的影 响。结果分析表明: 藻的炭化、燃烧过程与陆上木质类生物质差异较大, 且 藻在低温水热炭化反应后热值显著提升, 综合考虑低温水热炭化藻类生物质 以提高其热值的最佳方案是时间、盐浓度分别控制在 $8-10 \mathrm{~h} 、 0.05 \%$ 左右, 反应温度略大于 $240^{\circ} \mathrm{C}$ 。为清洁生物质领域的深入研究提供了一定的借鉴, 并且对于藻类生物质燃烧功能的开发具有重要意义。

关键词: 绿藻, 生物质, 低温水热炭化, 生物炭 